\title{
Expression of GAP-43, a Rapidly Transported Growth-Associated Protein, and Class II Beta Tubulin, a Slowly Transported Cytoskeletal Protein, Are Coordinated in Regenerating Neurons
}

\author{
Paul N. Hoffman \\ Departments of Ophthalmology and Neurology, The Johns Hopkins University School of Medicine, Baltimore, Maryland \\ 21205
}

\begin{abstract}
GAP-43 is a membrane-associated phosphoprotein enriched in elongating axons (Meiri et al., 1986; Skene et al., 1986). After an axon has been interrupted by cutting or crushing a nerve (axotomy), the portion of the axon disconnected from the cell body (distal stump) degenerates and is replaced by the outgrowth (elongation) of regenerating sprouts arising from the proximal stump. Previous studies have shown that increased amounts of pulse-labeled GAP-43 undergo fast axonal transport in regenerating neurons (Benowitz et al., 1981; Skene and Willard, 1981a, b). Using hybridization with a cloned cDNA probe, I now show that mRNA levels for GAP43 increase in lumbar sensory neurons of rat after regeneration is initiated by crushing the sciatic nerve; the relatively high levels of GAP-43 mRNA in regenerating neurons are comparable to those in the developing neurons of 5-d-old animals. I further demonstrate that the induction of GAP-43 expression in regenerating neurons coincides temporally with an increase in mRNA levels for class II beta tubulin (Hoffman and Cleveland, 1988), suggesting that the expression of these proteins is closely coordinated during axonal elongation.
\end{abstract}

Axonal elongation, a key event during both neuronal development and axonal regeneration, is associated with the increased expression of specific neuronal proteins. One of these proteins, GAP-43-also designated pp46, B-50, and F1, depending on the context in which it was investigated (Meiri et al., 1986; Benowitz and Routtenberg, 1987; Snipes et al., 1987)-is a membrane-associated phosphoprotein enriched in elongating axons (Meiri et al., 1986; Skene et al., 1986). Like other axonal proteins, GAP-43 is synthesized exclusively in neuron cell bodies; after entering the axon, it is translocated in the fast component of axonal transport (Skene and Willard, 1981a, b). Regenerative outgrowth correlates with a dramatic increase in the amount of pulse-labeled GAP-43 undergoing axonal transport

Received Apr. 11, 1988; revised Aug. 10, 1988; accepted Aug. 12, 1988.

This work was supported by a grant from the National Institutes of Health (NS22849). The author is the recipient of a Research Career Development Award from the National Institutes of Health (NS-00896). Special thanks to Dr. Mark Fishman for his insightful editorial comments and for providing the cloned DNA probe encoding GAP-43. I also thank Kristi Hambrecht, Kenneth Fahnestock, and Judith Coram for their excellent technical assistance. Cloned DNA probes were also kindly provided by Drs. Stephen Farmer ( $3^{\prime}$ untranslated region subclone of RBT.1) and Nicholas Cowan (NF68). In all cases, procedures performed on animals and the care of animals were in accordance with the guidelines of The Johns Hopkins University.

Correspondence should be addressed to Paul N. Hoffman, 5-167 Meyer Building, The Johns Hopkins Hospital, 600 N. Wolfe St., Baltimore, MD 21205.

Copyright (c) 1989 Society for Neuroscience $0270-6474 / 89 / 030893-05 \$ 02.00 / 0$ in regenerating neurons (Benowitz et al., 1981; Skene and Willard, $1981 \mathrm{a}, \mathrm{b})$. GAP-43 mRNA lcvels have bcen shown to bc greater in developing than mature neurons (Basi et al., 1987; Karns et al., 1987; Neve et al., 1987) and increased in regenerating sensory neurons 2 weeks after axonal injury (Basi et al., $1987)$ and in human CNS neurons injured by ischemia ( $\mathrm{Ng}$ et al., 1988), suggesting that some of the regulation occurs at the level of gene expression.

Axonal elongation also correlates with the expression of tubulin (Hoffman and Cleveland, 1988), a protein delivered by the slow component of axonal transport (Hoffman and Lasek, 1975) and directly involved in the process of axonal elongation (Yamada et al., 1971). Tubulin is a dimer composed of an alpha and a beta subunit. Alpha and beta tubulin are each encoded by multigene families (Sullivan and Cleveland, 1986). Within these families distinct tubulin isotypes can be distinguished on the basis of their unique carboxy-terminal amino acid sequences. There are 5 beta tubulin isotypes, each encoded by a separate gene (Lopata and Cleveland, 1987). Genes encoding 3 of these isotypes (classes I, II, and IV) have been cloned from rat (Bond et al., 1984; Farmer et al., 1984; Sullivan and Cleveland, 1986); in situ hybridization studies demonstrate that each of these isotypes is expressed in sensory neurons of rat (Hoffman and Cleveland, 1988). The expression of one of these beta tubulin isotypes (class II) is selectively induced during neuronal development and axonal regeneration; mRNA levels for the other isotypes (classes I and IV) change relatively little during development and regeneration (Hoffman and Cleveland, 1988). In contrast, neurofilament (NF) expression is reduced (compared to mature neurons) during development and regeneration (Hoffman et al., 1987; Hoffman and Cleveland, 1988). Thus, the developmental patterns of expression for class II beta tubulin and NF are recapitulated during axonal regeneration.

I was interested in examining the time course of GAP-43 expression during regeneration and to compare it to those of class II beta tubulin and the $68 \mathrm{kDa}$ NF protein (NF68). The observation that GAP-43 and class II beta tubulin expression are induced with similar time courses would suggest that the expression of these proteins is closely coordinated.

\section{Materials and Methods}

In situ hybridization. Sciatic nerves of anesthetized (chloral hydrate, 400 $\mathrm{mg} / \mathrm{kg}$, i.p.) 7-week-old male Sprague-Dawley rats were crushed twice for $30 \mathrm{sec}$ at the L4-L5 junction using no. 7 Dumont forceps. Unfixed dorsal root ganglia (DRG), which contain sensory neuron cell bodies, were removed from animals killed by overdose of anesthesia and immediately frozen in cryoprotective embedding medium. Cryostat sec- 


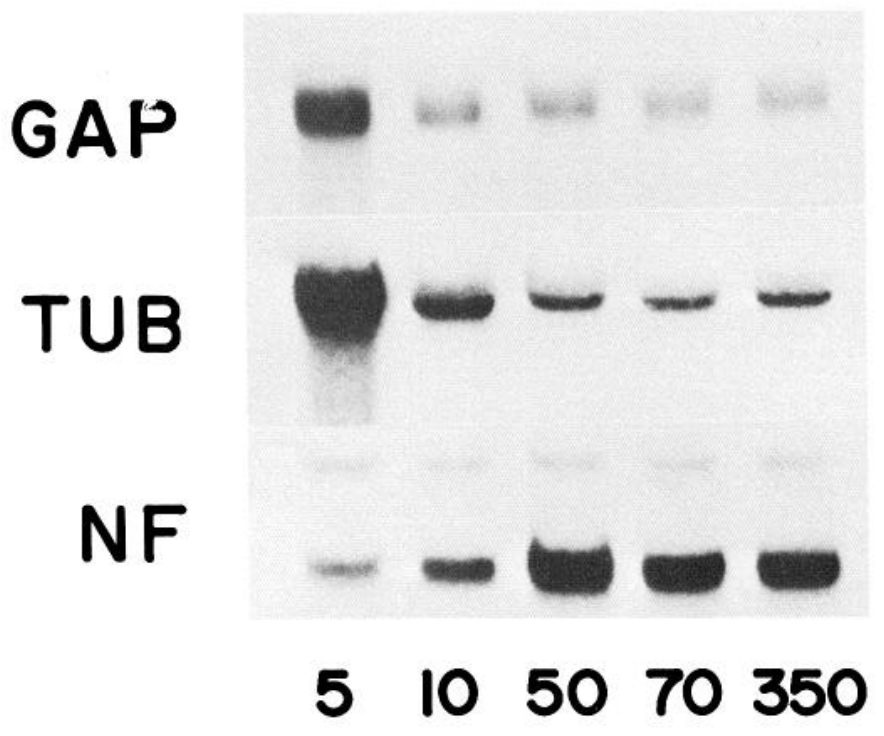

Figure 1. RNA blot analysis of mRNA levels during neuronal development. Total RNA was harvested from DRG of control animals at 5, $10,50,70$, and $350 \mathrm{~d}$ of age. GAP-43, class II beta tubulin and NF68 were identified by hybridization to appropriate cloned cDNAs. After hybridization with each cDNA probe, labeled hybrids were removed and the blot was rehybridized successively with each probe. GAP, autoradiogram of GAP-43 mRNAs; TUB, autoradiogram of class II beta tubulin mRNAs; $N F$, autoradiogram of NF68 mRNAs. Ten micrograms of RNA were analyzed on each lane. Autoradiograms were exposed for $1-3 \mathrm{~d}$.

tions $(8 \mu \mathrm{m})$ of ganglia obtained $4 \mathrm{~d}$ after axotomy and from age-matched control animals were transferred to gelatin-coated slides prior to fixation with $4 \%$ paraformaldehyde. Tissue sections were hybridized with ${ }^{35} \mathrm{~S}$ labeled cDNA probes using a published method (Lewis and Cowan, 1985a). A specific cloned cDNA probe encoding GAP-43 was previously described (Karns et al., 1987).

$R N A$ blots. At intervals between 1 and $56 \mathrm{~d}$ after bilateral sciatic nerve crush, animals were killed by overdose of anesthesia and L4 and L5 DRG were removed. Ganglia were removed in a similar manner from unoperated animals at $5,10,50,70$, and $350 \mathrm{~d}$ of age. Eight to 12 ganglia (from 2 or 3 animals, respectively) were pooled for RNA preparation (except in 5-d-old animals, in which case 25-30 ganglia were pooled). A major advantage of this system is that the nerve cell bodies can be completely harvested by removal of the DRG and can be prepared free of contamination by other populations of neurons. RNA isolated from these ganglia (Chirgwin et al., 1979) was separated on agarose-formaldehyde gels and transferred to nylon membranes for hybridization with ${ }^{32}$ P-labeled cDNA as previously described (Shank et al., 1978; Hoffman et al., 1987). A specific cloned cDNA probe encoding the $3^{\prime}$ untranslated region of class II beta tubulin gene of rat was a subclone of RBT.1 (Bond et al., 1984; Farmer et al., 1984); the cloned cDNA probe encoding NF68 was previously described (Lewis and Cowan, 1985b). Labeled hybrids were detected autoradiographically and quantitated using a computer-based video densitometric system (Loats Associates, Inc., Westminster, MD). After hybridization with each cDNA probe, labeled hybrids were removed and blots were rehybridized successively with each probe.

\section{Results}

Increased expression of GAP-43 during axonal regeneration GAP-43 is developmentally regulated in these sensory neurons (Karns et al., 1987). In order to demonstrate this regulation, RNA was isolated from DRG of unoperated animals at 5, 10, 50,70 , and $350 \mathrm{~d}$ of age (Fig. 1). GAP-43 mRNA levels were 4.5-fold higher at $5 \mathrm{~d}$ of age than in older animals (Fig. 1). GAP43 mRNA levels declined markedly between 5 and $10 \mathrm{~d}$ of age; thereafter, they remained relatively constant (Fig. 1).

Levels of GAP-43 mRNA were then examined in RNA harvested from sensory neurons at various times after axonal regeneration was induced by crushing the sciatic nerve. A representative RNA blot is shown in Figure 2; quantitation for this particular blot is illustrated in Figure 3. Comparable results were obtained from RNA blots performed in 4 independent experiments. These analyses demonstrated that GAP-43 mRNA levels were increased 2.5 -fold by $1 \mathrm{~d}$ after axotomy, and 11.5 -fold at $2 \mathrm{~d}$ after axotomy (Figs. 2, 3). GAP-43 mRNA levels remained elevated between 4 and $14 \mathrm{~d}$, returning to control levels by 28 d after axotomy (Figs. 2, 3). Relatively high levels of GAP-43 expression have been previously reported in cultured embryonic neurons during axonal elongation (Karns et al., 1987) and in regenerating sensory neurons (Basi et al., 1987).

\section{Induction of GAP-43 and class II beta tubulin expression coincide in regenerating neurons}

Like GAP-43, the expression of class II beta tubulin was also higher in developing than mature sensory neurons; a marked

Figure 2. RNA blot analysis of mRNA levels during axonal regeneration. Total RNA was harvested from DRG of 5-dold animals $(N), 10$-week-old animals $(M)$, and at various times after crushing the sciatic nerve (in $\mathrm{d}$, shown below each lane). GAP-43, class II beta tubulin, and NF68 were identified by hybridization to appropriate cloned cDNAs. After hybridization with each cDNA probe, labeled hybrids were removed and the blot was rehybridized successively with each probe. $G A P$, autoradiogram of GAP-43 mRNAs; TUB, autoradiogram of class II beta tubulin mRNAs; $N F$, autoradiogram of NF68 mRNAs. Hybridization of this blot with probes for NF68 and class II tubulin was shown previously (Hoffman and Cleveland, 1988). Ten micrograms of RNA were analyzed on each lane. Autoradiograms were exposed for 1-3 d.

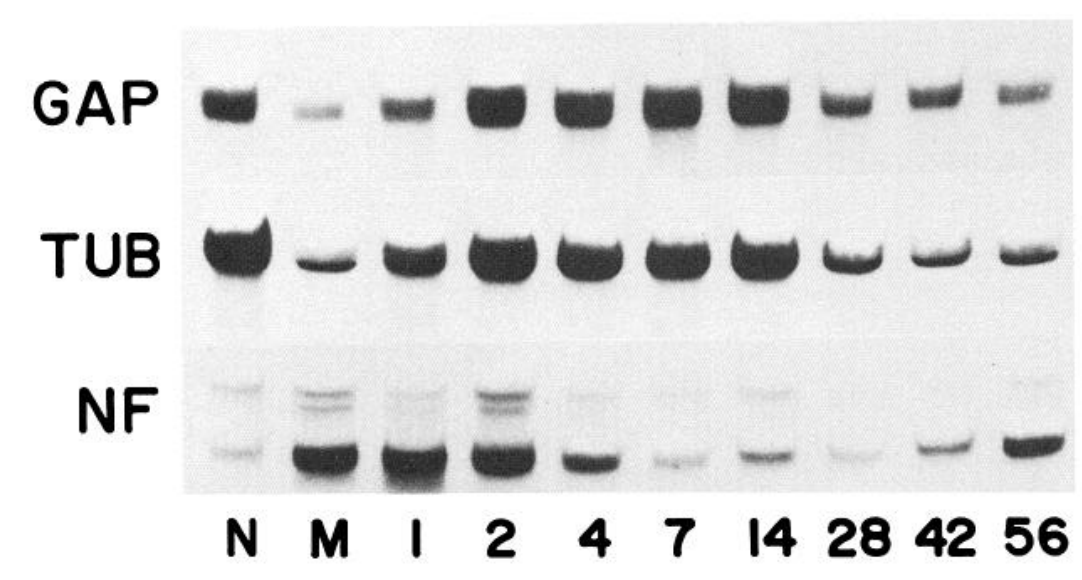


reduction in tubulin mRNA levels occurred between 5 and 10 $\mathrm{d}$ of age (Fig. 1). The expression of class II beta tubulin was increased in regenerating neurons (Hoffman and Cleveland, 1988); mRNA levels were increased 2 -fold by $1 \mathrm{~d}$ after axotomy, and 6 -fold at $2 \mathrm{~d}$ after axotomy (Figs. 2, 3). Class II beta tubulin mRNA levels remained elevated between 4 and $14 \mathrm{~d}$, returning to control levels by $28 \mathrm{~d}$ after axotomy (Figs. 2, 3). The time course for this induction of class II beta tubulin coincided exactly with the increased expression of GAP-43 in regenerating neurons (Fig. 3).

In contrast to GAP-43 and class II beta tubulin, mRNA levels for NF68 were relatively low (compared with mature neurons) during both development and regeneration (Hoffman and Cleveland, 1988). NF68 mRNA levels increased dramatically between 5 and $10 \mathrm{~d}$ of age and between 10 and $50 \mathrm{~d}$; thereafter, mRNA levels remained relatively constant (Fig. 1). Reduction in NF68 mRNA levels in regenerating neurons was first seen at $4 \mathrm{~d}$ after axotomy; maximal reduction (to $7 \%$ of control values) occurred at $28 \mathrm{~d}$ after axotomy (Figs. 2, 3). A significant increase towards control levels of NF68 mRNA was seen at $56 \mathrm{~d}$ after axotomy (Figs. 2, 3). Previously, we have shown that NF68 expression in these neurons returns to control levels by $70 \mathrm{~d}$ after nerve crush (Hoffman et al., 1987).

\section{In situ hybridization studies}

In situ hybridization studies demonstrated that approximately $20 \%$ of neurons in control ganglia expressed GAP-43 at relatively high levels compared with the remaining control neurons (Fig. 4). The neuronal expression of GAP-43 was markedly increased in all neurons during axonal regeneration (Fig. 4). This response to injury was not restricted to neurons with high basal levels, in that the whole population of neurons exhibited high levels of GAP-43 expression after injury (Fig. 4).

\section{Discussion}

Coordinated expression of GAP-43 and class II beta tubulin in regenerating neurons

Increases in mRNA levels for GAP-43, a rapidly transported membrane-associated protein, and class II beta tubulin, a slowly transported cytoskeletal protein, coincided in regenerating neurons (Figs. 2, 3), suggesting that the expression of these proteins is closely coordinated. The increased expression of these genes is selective. Expression of NF, the other major cytoskeletal protein undergoing slow axonal transport, is reduced in regenerating neurons (Hoffman et al., 1987; Figs. 2, 3). Expression is also reduced for other rapidly transported proteins (Karlstrom and Dahlstrom, 1973); mRNA levels for tyrosine hydroxylase, a key enzyme in catecholamine synthesis, are reduced in sympathetic neurons during axonal regeneration (Koo et al., 1988).

\section{$G A P-43$ expression and axonal growth}

The present findings demonstrate that the expression of GAP43 , as reflected by increased mRNA levels, correlates with axonal regeneration. Thus, at least some of the increase in the axonal transport of GAP-43 that occurs during regeneration (Skene and Willard, 1981a, b) is mediated by a change at the level of gene expression (Basi et al., 1987). Similarly, levels of GAP-43 expression are also high during the elongation of developing axons (Karns et al., 1987). Taken together, these observations suggest that the developmental program for GAP-43 expression is recapitulated during axonal regeneration.

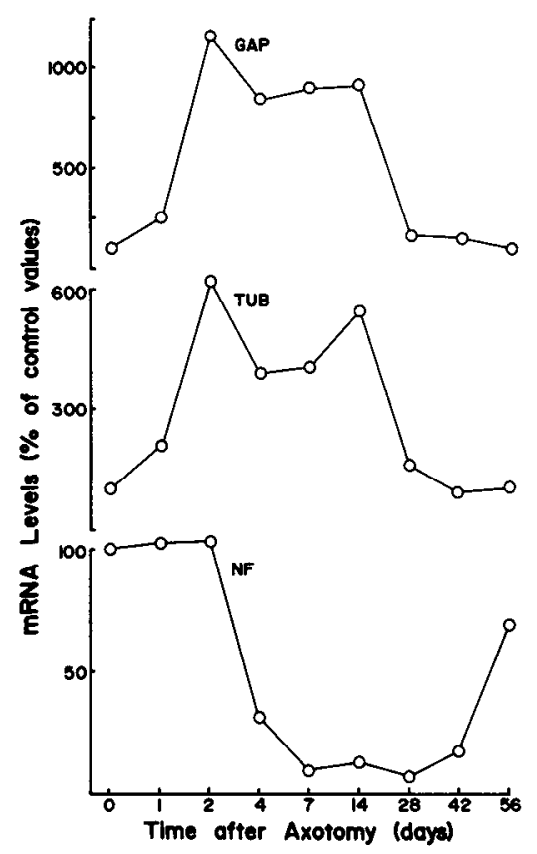

Figure 3. Quantitation of hybrid formation for GAP-43, class II beta tubulin, and NF68 during axonal regeneration. Autoradiographic signals for the blots shown in Figure 2 were quantitated using a computer-based video densitometry system (Loats Associates, Inc., Westminster, MD). Levels were normalized in relation to those in 10-week-old control animals $(0 \mathrm{~d})$ and plotted as a function of time after axotomy.

Although induction of GAP-43 correlates with axonal elongation, its persistence in certain adult neurons suggests that its role is not limited to elongation. It has been proposed that GAP43 functions in several forms of structural remodeling, including, but not limited to elongation (Benowitz and Routtenberg, 1987; Karns et al., 1987; Neve et al., 1987). Thus, GAP-43 expression persists in hippocampal (Neve et al., 1987; S. M. de la Monte, H. J. Federoff, S. C. Ng, E. Grabczyk, and M. C. Fishman, unpublished observations) and olfactory neurons (de la Monte et al., unpublished observations), populations where synaptic remodeling occurs throughout life. Whether the population of mature sensory neurons in DRG with persistent GAP43 expression (Fig. 4) is also engaged in nerve terminal remodeling remains to be determined.

\section{Cytoskeletal gene expression and axonal growth}

The role of tubulin in axonal elongation is well-established (see Hoffman and Cleveland, 1988). Microtubules, polymers composed primarily of tubulin, are the principal cytoskeletal elements in both developing axons and regenerating sprouts (Berthold, 1978). The induction of class II beta tubulin mRNA levels correlates closely with the time course of regenerative outgrowth (Hoffman and Cleveland, 1988).

In contrast to GAP-43 and class II beta tubulin, NF cxpression correlates with radial, rather than longitudinal growth of axons (Hoffman et al., 1988). NF are major intrinsic determinants of axonal caliber in myelinated nerve fibers, where NF number correlates directly with axonal cross-sectional area (Friede and Samorajski, 1970; Weiss and Mayr, 1971; Berthold, 1978; Hoffman et al., 1984). Prior to undergoing radial growth, developing axons are small in caliber $(<1 \mu \mathrm{m}$ in diameter), are highly enriched in microtubules, and contain relatively few NF (Peters 

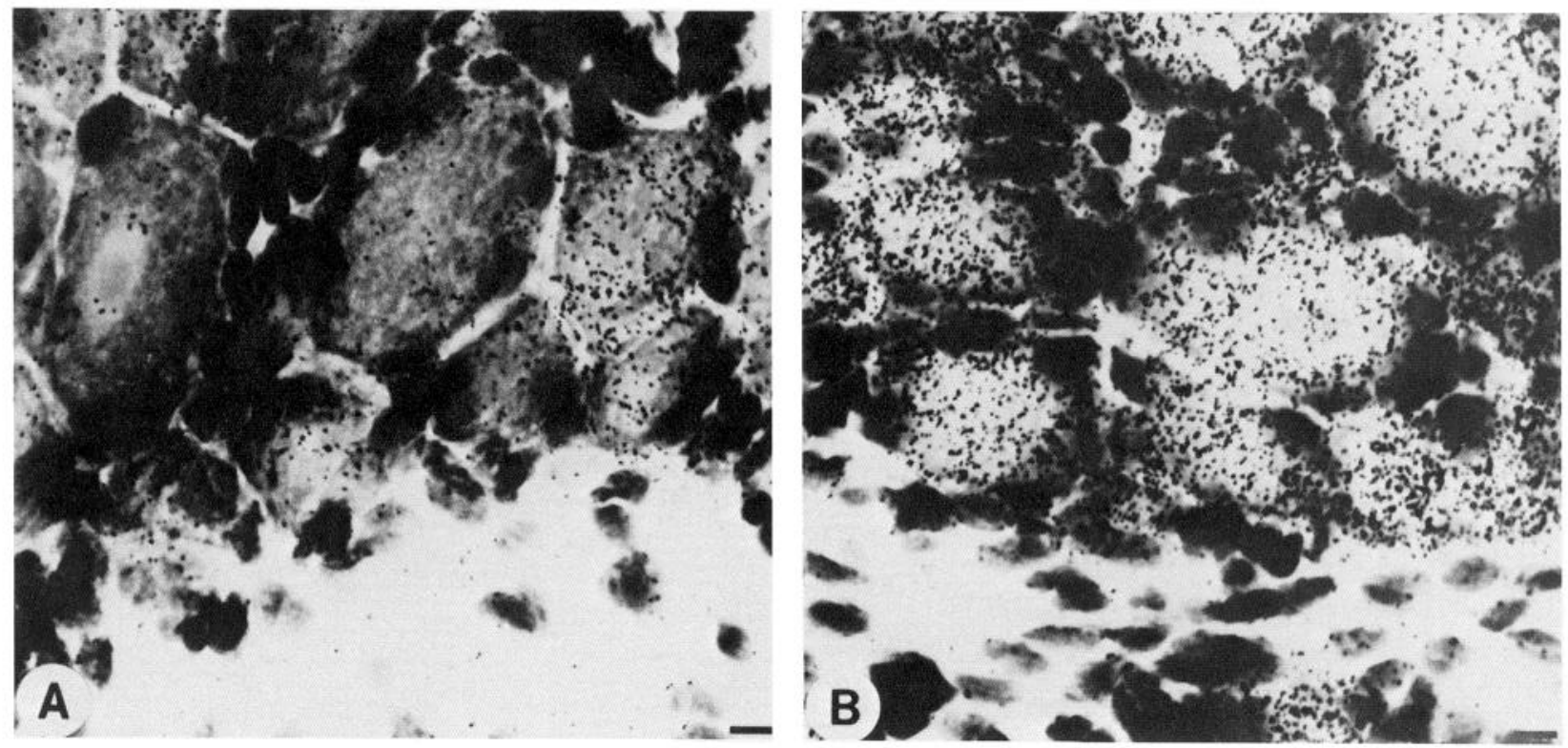

Figure 4. Localization of GAP-43 mRNAs within sensory neurons. In situ hybridization of ${ }^{35}$ S-labeled cDNA that specifically hybridizes with GAP-43 mRNAs was performed on tissue sections containing $(A)$ control sensory neurons (from unoperated 10-week-old animals) and $(B)$ regenerating neurons $4 \mathrm{~d}$ after axotomy. Autoradiograms were exposed for $5 \mathrm{~d}$. Scale bars, $10 \mu \mathrm{m}$.

and Vaughn, 1967; Berthold, 1978). This paucity of axonal NF is consistent with the low level of NF expression in developing neurons (Fig. 1). Reduction in NF expression after axotomy (Figs. 2, 3) correlates with a decrease in axonal caliber in the proximal stump (Hoffman et al., 1984, 1987).

\section{Regulation of gene expression during axonal growth}

Neuron-target interactions appear to play an important role in regulating NF gene expression (Hoffman et al., 1988). The role of such interactions in the regulation of GAP-43 and class II beta tubulin expression remains to be established. Both targetdependent and target-independent regulation of GAP-43 transport have been reported in developing mammalian neurons. For example, in cultured embryonic sensory neurons, the interaction of axons with appropriate targets in vitro correlates with a decline in GAP-43 transport (Baizer and Fishman, 1987). On the other hand, removal of normal target interactions by axotomy does not prevent the developmental decline in GAP43 transport in pyramidal tract neurons of the mammalian CNS (Kalil and Skene, 1986).

The effect of target removal on GAP-43 transport has been assessed during optic nerve regeneration in goldfish. Benowitz et al. (1983) compared the amounts of pulse-labeled GAP-43 undergoing axonal transport during normal regeneration and after target (optic tectum) ablation and found no differences at $10 \mathrm{~d}, 30 \mathrm{~d}$, and 5 months after axotomy. In contrast, Grafstein et al. (1987) found that although the large, initial decline in GAP-43 transport at 3 weeks after axotomy occurred in the absence of targets, target ablation prevented the return of transport to preaxotomy levels by 12 weeks after axotomy.

Some of these seemingly contradictory results may be explained in part by differences in species or by differences in GAP-43 control in central versus peripheral neurons. Additionally, the accumulation of GAP-43 in axons may be regulated at several levels, including synthesis, transport, and degradation. Thus, whether GAP- 43 is regulated by target interactions is an unresolved issue. Studies currently underway are designed to examine the role of neuron-target interactions in the induction of GAP-43 and class II beta tubulin expression after axotomy and the subsequent return of expression to preaxotomy levels.

\section{References}

Baizer, L., and M. C. Fishman (1987) Recognition of specific targets by cultured dorsal root ganglion neurons. J. Neurosci. 7: 2305-2311.

Basi, G. S., R. D. Jacobson, I. Virag, J. Schilling, and J. H. P. Skene (1987) Primary structure and transcriptional regulation of GAP-43, a protein associated with neuronal growth. Cell 49: 785-791.

Benowitz, L. I., V. E. Shashoua, and M. Yoon (1981) Specific changes in rapidly transported proteins during regeneration of goldfish optic nerve. J. Neurosci. 1: 300-307.

Benowitz, L. I., and A. Routtenberg (1987) A membrane phosphoprotein associated with neural development, axonal regeneration, phospholipid metabolism, and synaptic plasticity. Trends Neurosci. 10: $527-532$.

Benowitz, L. I., M. G. Yoon, and E. R. Lewis (1983) Transported proteins in the regenerating optic nerve: Regulation by interactions with the optic tectum. Science 222: 185-188.

Berthold, C. H. (1978) Morphology of normal peripheral axons. In Physiology and Pathobiology of Axons, S. G. Waxman, ed., pp. 3-63, Raven, New York.

Bond, J. F., G. S. Robinson, and S. R. Farmer (1984) Differential expression of two neural cell-specific beta-tubulin mRNAs during rat brain development. Mol. Cell. Biol. 4: 1313-1319.

Chirgwin, J. M., A. E. Przybyla, R. J. MacDonald, and W. J. Rutter (1979) Isolation of biologically active ribonucleic acid from sources enriched in ribonuclease. Biochemistry 18: 5294-5299.

Farmer, S. R., J. F. Bond, G. S. Robinson, D. Mbangkollo, M. J. Fenton, and E. M. Berkowitz (1984) Differential expression of the rat betatubulin multigene family. In Molecular Biology of the Cytoskeleton, G. G. Borisy, D. W. Cleveland, and D. B. Murphy, eds., pp. 333342. Cold Spring Harbor Laboratory, Cold Spring Harbor, NY.

Friede, R. L., and T. Samorajski (1970) Axon caliber relates to neurofilaments and microtubules in sciatic nerve fibers of rats and mice. Anat. Rec. 167: 379-387.

Grafstein, B., D. W. Burmeister, C. M. McGuinness, G. W. Perry, and J. R. Sparrow (1987) Role of fast axonal transport in regeneration of goldfish optic axons. Prog. Brain Res. 71: 113-120. 
Hoffman, P. N., and D. W. Cleveland (1988) Neurofilament and tubulin expression recapitulates the developmental program during axonal regeneration: Induction of a specific beta tubulin isotype. Proc. Natl. Acad. Sci. USA 85: 4530-4533.

Hoffman, P. N., and R. J. Lasek (1975) The slow component of axonal transport: Identification of the major structural polypeptides of the axon and their generality among mammalian neurons. J. Cell Biol. 66: 351-366.

Hoffman, P. N., J. W. Griffin, and D. L. Price (1984) Control of axonal caliber by neurofilament transport. J. Cell Biol. 99: 705-714.

Hoffman, P. N., D. W. Cleveland, J. W. Griffin, P. W. Landes, N. J. Cowan, and D. L. Price (1987) Neurofilament gene expression: A major determinant of axonal caliber. Proc. Natl. Acad. Sci. USA 84 $3472-3476$.

Hoffman, P. N., E. H. Koo, N. A. Muma, J. W. Griffin, and D. L. Price (1988) Role of neurofilaments in the control of axonal caliber in myelinated nerve fibers. In Intrinsic Determinants of Neuronal Form and Function, R. J. Lasek and M. M. Black, eds., pp. 389-402, Liss, New York.

Kalil, K., and J. H. P. Skene (1986) Elevated synthesis of an axonally transported protein correlates with axon outgrowth in normal and injured pyramidal tracts. J. Neurosci. 6: 2563-2570.

Karlstrom, L., and A. Dahlstrom (1973) The effect of different types of axonal trauma on the synthesis and axonal transport of amine storage granules in rat sciatic nerve. J. Neurobiol. 4: 191-200.

Karns, L. R., S.-C. Ng. J. A. Freeman, and M. C. Fishman (1987) Cloning of complementary DNA for GAP-43, a neuronal growthrelated protein. Science 236: 597-600.

Koo, E. H., P. N. Hoffman, and D. L. Price (1988) Levels of neurotransmitter and cytoskeletal protein mRNAs during nerve regeneration in sympathetic ganglia. Brain Res. 449: 361-363.

Lcwis, S. A., and N. J. Cowan (1985a) Temporal expression of mousc glial fibrillary acid protein mRNA studied by a rapid in situ hybridization procedure. J. Neurochem. 45: 913-919.

Lewis, S. A., and N. J. Cowan (1985b) Genetics, evolution, and expression of the 68,000-mol-wt neurofilament protein: Isolation of a cloned cDNA probe. J. Cell Biol. 100: 843-850.

Lopata, M. A., and D. W. Cleveland (1987) In vivo microtubules are copolymers of available beta-tubulin isotypes: Localization of each of six vertebrate beta-tubulin isotypes using polyclonal antibodies elicited by synthetic peptide antigens. J. Cell Biol. 105: 1707-1720.

Meiri, K. F., K. H. Pfenninger, and M. B. Willard (1986) Growthassociated protein, GAP43, a polypeptide that is induced when neu- rons extend axons, is a major component of growth cones and corresponds to pp46, a major polypeptide of a subcellular fraction enriched in growth cones. Proc. Natl. Acad. Sci. USA 83: 3537-3541.

Nevc, R. L., N. I. Perrone-Bizzozero, S. Finkelstein, H. Zwiers, D. M. Kurnit, and L. I. Benowitz (1987) The neuronal growth-associated protein GAP-43 (B-50, F1): Neuronal specificity, developmental regulation and regional distribution of the human and rat mRNAs. Mol. Brain Res. 2: 177-183.

Ng, S. C., S. M. de la Monte, G. L. Conboy, L R. Karns, and M. C Fishman (1988) Cloning of human GAP-43: Growth association and ischemic resurgence. Neuron $1: 133-139$.

Peters, A., and J. E. Vaughn (1967) Microtubules and filaments in the axons and astrocytes of early postnatal optic nerves. J. Cell Biol. 32: 113-119.

Shank, P. R., S. H. Hughes, H.-J. Kung, J. E. Majors, N. Quintrell, R. V. Guntaka, J. M. Bishop, and H. E. Varmus (1978) Mapping unintegrated avian sarcoma virus DNA: Termini of linear DNA bear 300 nuclcotides present once or twice in two species of circular DNA. Cell 15: 1383-1395.

Skene, J. H. P., and M. B. Willard (1981a) Changes in axonally transported proteins during axon regeneration in toad retinal ganglion cells. J. Cell Biol. 89: 86-95.

Skene, J. H. P., and M. B. Willard (1981b) Axonally transported proteins associated with axon growth in rabbit central and peripheral nervous systems. J. Cell Biol. 89: 96-103.

Skene, J. H. P., R. D. Jacobson, G. J. Snipes, C. B. McGuire, J. Norden, and J. A. Freeman (1986) A protein induced during nerve growth (GAP-43) is a major component of growth-cone membranes. Science 233: 783-786.

Snipes, G. J., S. Y. Chan, C. B. McGuire, B. R. Costello, J. J. Norden, J. A. Freeman, and A. Routtenberg (1987) Evidence for the coidentification of GAP-43, a growth-associated protein, and $F 1$, a plasticity-associated protein. J. Neurosci. 7: 4066-4075.

Sullivan, K. F., and D. W. Cleveland (1986) Identification of conserved isotype-defining variable region sequences for four vertebrate beta tubulin polypeptide classes. Proc. Natl. Acad. Sci. USA 83: 43274331.

Weiss, P. A., and R. Mayr (1971) Organelles of neuroplasmic ("axonal") flow: Neurofilaments. Proc. Natl. Acad. Sci. USA 68: 846850.

Yamada, K. M., B. S. Spooner, and N. K. Wessels (1971) Ultrastructure and function of growth cones and axons of cultured nerve cells. J. Cell Biol. 49: 614-635. 